\title{
Multiplicação vegetativa e eliminação dos fenômenos de degenerescência nos clones de mandioca (Manihot esculenta Crantz) cultivados in vitro
}

\author{
L. Fereol ( $\left.{ }^{*}\right)$ \\ G Ducreux $\left({ }^{*}\right)$
}

\begin{abstract}
Resumo
Os clones africanos da mandioca cultivados tradicionalmente na Africa, apresentam freqüentemente certos sintomas de degenerescência (African Cassava mosaic). A repartiçāo, a transmissāo e a progressăo do agente patogênico, foram estudadas a partir de experiências feitas através de transplantaçōes ou enxertos, guardando como referência do clone indene de sintomas, proveniente do Vietnã. A cultura in vitro permitiu o aperfeiçoamento dos tratamentos de termoterapia conduzindo à cura de todos os clones estudados, e à obtenção de uma multiplicação vegetativa acelerada, que permite a reconstituição de clones saudáveis em pouco- tempo.
\end{abstract}

\section{INTRODUÇÃo}

A mandioca (Manihot esculenta Crantz) é, correntemente, multiplicada por meio do plantio de manivas. A prática ancestral desta multiplicação vegetativa favoreceu o aparecimento de fenômenos de degenerescência que se exprimem mostrando um fraco desenvolvimento ao nivel da parte aérea, assim como por meio de mosáicos e de deformações nas folhas. Pcr outro lado, a produção média dos tubérculos pode ser diminuída de $30 \%$ ou mais, em função da sensibilidade da variedade (Beck \& Chant. 1958; Magoon, 1967).

O aparecimento destas perturbações, conhecidas geralmente pelo nome de mosáicos, tem duas origens diferentes (Silva, 1962; Kitajima \& Costa, 1966): "African Cassava Mosaic" (originário da Africa), e "Cassava Common Mosaic" (originário da América).

Estas duas formas distinguem-se igua!mente ao nivel da manifestaçăo dos sintomas Elas säo transinissiveis por meio de estacas (manivas) e enxertos, mas, segundo o nosso conhecimento, apenas a forma americana foi identificada como sendo de natureza viral (Storey \& Nichols, 1938; Kitajima \& Costa, 1966). O nos. so trabalho é sobre o "African Cassava Mosaic", cujo agente patológico não foi ainda isolado.

Diversos métodcs permitem chegar a uma erradicação dos sintomas de degenerescência e foram aplicados à mandioca com maior ou menior sucesso. Assim, a existência de genes de resistência em espécies selvagens (Jennings, 1957, 1960), permitiu obter variedades hibridas resistentes ao mosáico (Maggon et al., 1970). Tentativas feitas na variedade "Kalikaian" (de origem africana) permitiram a obtenção de $60 \%$ de plantas saudáveis a partir de regenerações em ápex meristemáticos isolados (Kartha \& Gamborg, 1974).

Interessamo-nos pelo método termoterapêutico, utilizado até esta data in vivo sobre estacas transplantadas ou em plantas inteiras (Chant, 1959). Este método apresentava dois inconvenientes fundamentais: fraca taxa de cura e a lentidăo da multiplicação vegetativa.

Para resolver estes prob!emas, procuramos beneficiar-nos das vantagens apresentadas pela cultura in vitro.

A utilização desta técnica, para os tratamentos de termoterapia já mencionados, de excelentes resultados, em particular no caso da videira (Galzy, 1964), para a qual este metodo já passou ao estado de aplicação prática (Valat \& Mur, 1976) e no da batatinha (Nozeran et al., 1977). Outro interesse destas culturas in vitro é que elas permitem acelerar. em grandes proporções, a taxa de multiplicação vegetativa.

Efetivamente, se nos situarmos num caso de multiplicação "conforme", queremos com isto dizer que ela é conservadora do patrimônio heriditário (Nozeran \& Bancilhon, 1972), é possível obter um rítmo elevado de multiplicação vegetativa e, conseqüentemente, um ganho de tempo apreciável na reconstituição de clo-

(*) - Laboratório de Estudos e Exploreção do Polimorfismo Vegetal associado ao C.N.R.S. - Université Paris-Sud. 91405 ORSAY CEDEX - France. 
nes bem sucedidos. Este método revelou-se já particularmente eficaz, quando aplicado a vários materiais de estudo. Citemos, entre outros: Vitis (Favre, 1970, 1973), Citrus (Bouzid, 1971, e Bouzid \& Lasram, 1973), batata-doce (Sihaschackr, 1974), batatinha (Grenan, 1976), ananás (Pannetier \& Lanaud, 1976).

\section{MATERIAL E MÉtodos}

\section{A - CARACTERISTICAS DO MATERIAL}

\section{1) A origem dos clones:}

Utilizamos 7 clones apresentando ou não sintomas de degenerescência (Quadro 1) 6 destes clones são de origem africana: "H $\mathrm{H}_{88}$ ". "Ho", "C B", "M Bengui", "Kataoli", "Abidjan"; a sétima é originária da baía de Along (Vietnã) .

O material, constituído de estacas, foi colocado numa estufa tropicalizada, possuindo as seguintes condições médias: $25-30^{\circ} \mathrm{C}$, umidade relativa de $80 \%$, fotoperiodo $-12 \mathrm{~h}$.

\section{2) Sintomas e graus de intensidade da doença :}

Os sintomas são essencialmente constatáveis ao nivel do aparelho vegetativo e particularmente ao nivel das folhas: deformações, mosaicos (Fig. 1).

A severidade dos sintomas é variável segundo os clones doentes e. no próprio local, os graus de intensidade da doença foram atribuídos em função da natureza e da importância das modificações manifestadas nas plantas atingidas (Storey \& Nichols, 1938; Cours,
1951). Adaptamos, para este trabalho, os critérios de Cours, que permitem uma notação de 0 (planta saudavel) a 5 (planta muito modificada pela doença) (Quadro 1).

\section{B - INDICAÇÕES FITOPATOLÓGICAS}

\section{1) Transmissão e circulação do agente pato- lógico}

Para a experiência e para os contro!es, a transmissão da doença é realizada numa estufa, a partir de enxertos em fenda. Geralmente, - clone saudável "Baía de Along", tomado como referência, é utilizado como garfo sobre o cavalo doente. O testemunho, quanio ao efeito do enxerto, é obtido quando realizamos a associação "Baía Along"/ "Baía Along". A circulação e a velocidade de progressão do agente patogênico são analisadas quando associamos à variação do tamanho do garfo as transplantações nó a nó realizadas a tempos variáveis após o início da experiência.
2) Controle da presença do agente pato- gênico

A observação dos sintomas morfológicos está associada à realização dos enxertos. Consideramos como indenes da doença, os indivíduos sem sintomas e não contagiosos relativamente a garfos sensíveis (Baía de Along) ao fim de 4 meses. Vários enxertos complementares permitem afirmar este diagnóstico.

\section{3) Aplicação da termoterapia}

Estas experiências são realizadas em plantas cultivadas in vitro apresentando 5 a 6 folhas totalmente desenvolvidas. Os tubos de

QUADRO 1 - Intensidade de ataque do vírus Mosaico Africano da Mandioca, com anotaçōes, segundo a escala de Cours (1959), nos diferentes clones de mandioca utilizados, cultivados em estufa

\begin{tabular}{l|l|l|l}
\hline \multicolumn{1}{c|}{ Clones } & \multicolumn{1}{c|}{$\begin{array}{c}\text { Estado } \\
\text { fitossanitário }\end{array}$} & Origem geográfica & $\begin{array}{c}\text { Intensidade do Mosáico } \\
\text { (escala de Cours) }\end{array}$ \\
\hline Baía de Along & Saudável & Vietnã & 0 \\
$\mathrm{H}_{\infty}$ & Saudável & Costa de Marfím & 0 \\
$\mathrm{H}_{60}$ & Doente & Costa de Marfim & 1 \\
$\mathrm{H}_{58}$ & Doente & Madagáscar & 1 \\
$\mathrm{C} B$ & Doente & Costa de Marfím & 1 \\
Mbengui & Doente & Togo & 2 \\
Kataoli & Doente & Togo & 3 \\
Abidjan & Doente & Costa de Marfim & 4 \\
\hline
\end{tabular}



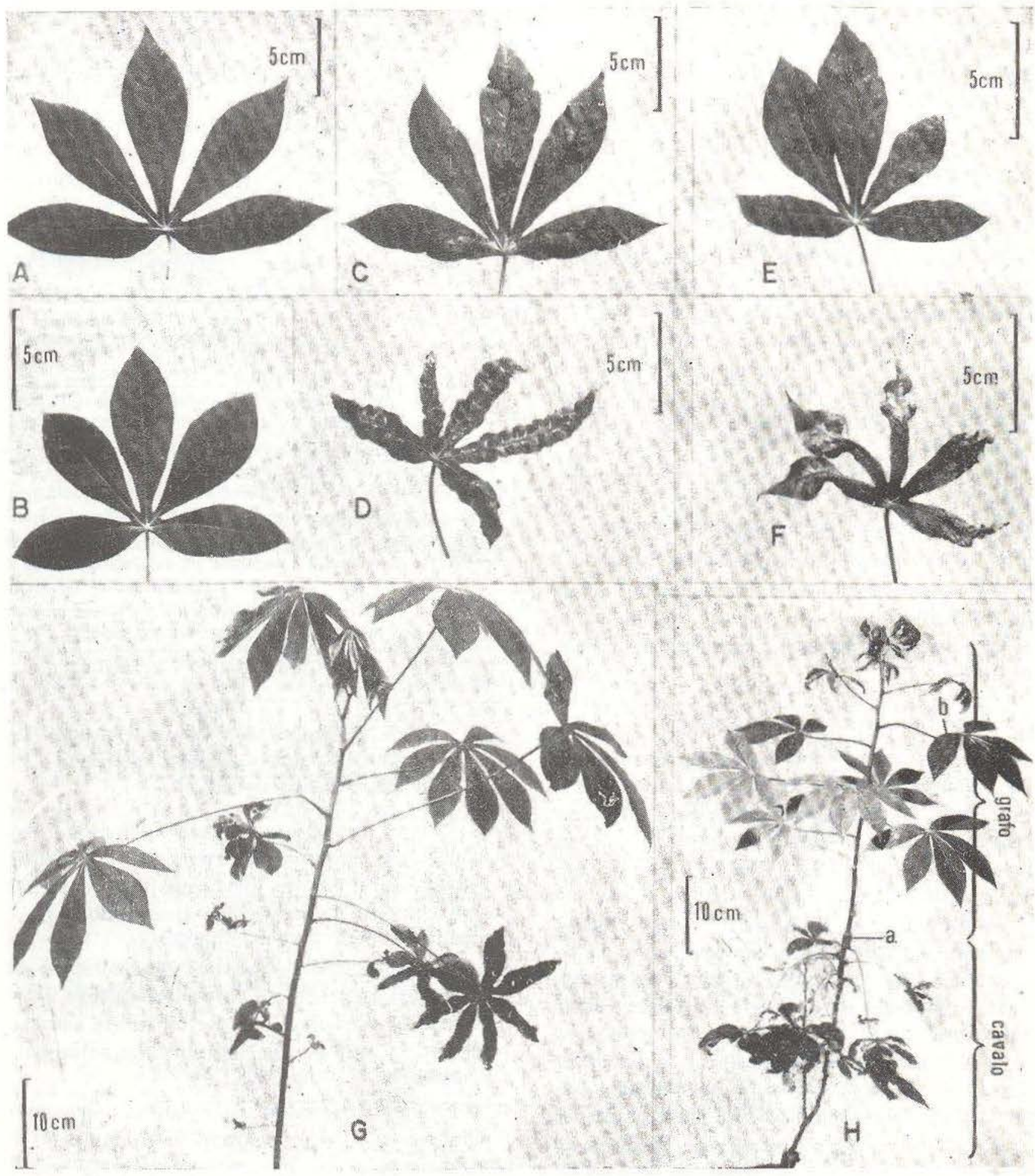

Fig. 1 - A a F - Exemplos de diferentes graus de intensidade da degenerescência: A) $I_{0}\left(" H_{50}\right.$ " saudável); B) $I_{0}$ ("Baía de Along" saudável); C) $\mathrm{I}_{1}\left(\right.$ " $\mathrm{H}_{60}$ " doente); D) $\mathrm{I}_{3}$ ("Kataoii" doente); E) "Baía de Along" contaminado pelo " $H_{60}$ " doente; F) "Baía de Along" contaminado pelo "Kataoli" doente; G) Variação da expressão dos sintomas foliares da doença num indivíduo do clone "C B"; H) Enxerto de uma estaca do clone saudável "Baia de Along" num "Abidjan" doente (Enxerto em fenda). Resultados obtidos, 6 semanas após a enxertia. - Notar a expressão da doença no cimo da estaca (a, saliência devida ao enxerto; b, primeira folha exprimindo os sintomas da doença). 
ensaio. colocados em estufas de tamanho reduzido $(104 \times 48 \times 84)$ são submetidos às seguintes condições: temperatura $36-37^{\circ} \mathrm{C}$ ou $39-40^{\circ} \mathrm{C}$ segundo o tratamento administrado, luz artificial 3500 lux, fotoperíodo $12 \mathrm{~h}$, umidade elevada.

\section{C - TÉCNICAS DE CULTURA "IN VITRO"}

\section{1) Início da cultura}

No início, as culturas são constituídas de frações de caule, possuindo um gomo extraído do material cultivado na estufa.

As amostras são primeiramente esterilizadas em álcool a $70^{\circ}$ (10 segundos), depois em hipoclorito de cálcio $(17 \mathrm{~g} / 1$ durante $30 \mathrm{minu}$. tos) e, finalmente, lavadas em água destilada estéril ( 3 banhos de 15 minutos). Estas amostras são depois transplantadas para um tubo pyrex (diâmetro $2,5 \mathrm{~cm}$ ) num meio nutritivo de KNOP diluido pela metade e completado pela solução de oligo-elementos de Berthelot.

A partir desta primeira implantação, diversas transplantações por estaca sucessivas, in vitro, permitem a constituição de lotes experimentais.

\section{2) Regresso às condições naturais}

Após as experiências, os individuos tratados, bem como os testemunhos, depois de serem cultivados in vitro são transferidos para a estufa, ao estado de 5 a 6 folhas já bem desenvolvidas e tratadas segundo o protocolo indicado (Fig. 2).

As observaçōes e os controles são realizados 4 meses mais tarde, tomando como referência os indivíduos sãos ao início desta pesquisa e segundo um dispositivo experimental totalmente casualizado. Quatro (4) petições são realizadas com o material: 1) saudável não cuidada pela termoterapia, 2) saudável tratado, 3) doente não tratado e 4) doente tratado.

As observaçōes concernem à presença ou ausência de sintomas e sobre as seguintes medidas: tamanho dos indivíduos, número de rós, superfície foliar e rendimento sobre o peso dos tubérculos.

Os resultados são analisados segundo o método de análise de variância e de compara. ção das médias pelo teste dos contrastes de SCIFFE.

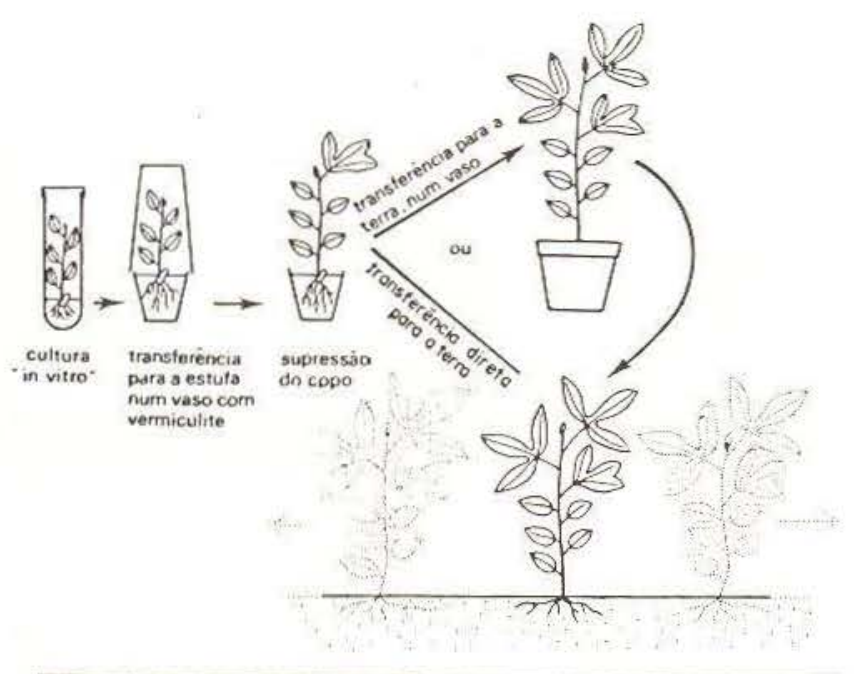

Fig. 2 - Esquema da transferência para a estufa, das plantas cultivadas in vitro. Os indivíduos, tirados dos tubos e libertados do agar, são depois plantados em vasos com vermiculite. Estas plantas são cobertas por um copo, formando um circuito fechado e guardando uma higrometria que é comparável à do tubo e evitando uma dessecaçăo brusca do material. O copo é tirado 8 a 10 dias depois. Regamos as culturas de 2 em 2 ou de 3 em 3 dias. com uma solução nutritiva de Knop diluido a metade. Dez dias depois da supressāo do copo, estas plantas sāo postas na terra.

\section{RESULTADOS}

\section{A - ASPECTOS MORFOLÓGICOS E VARIAÇÃo DA EXPRESSÃO DOS SINTOMAS DURANTE O DESENVOLVIMENTO}

Nos clones apresentando uma grande intensidade de sintomas de mosaico ("Kataoli", "Abidjan"), todas as folhas são atingidas. Em contrapartida, naqueles em que a doença se manifesta com menor intensidade [ " $\mathrm{H}_{\infty 0}$ ", ${ }^{\circ} \mathrm{C}$ B"), a expressão dos sintomas observa-se de forma desigual (Fig. 3). Algumas folhas apresentam os mosaicos e as deformações caracteristicas, e outras se mostram aparentemente saudáveis.

Observaçōes mais sistemáticas, realizadas num clone "C B", mostram que a intensidade da expressão dos sintomas pode variar muito de uma folha à outra (Fig. 1G). Estas variaçōes não parecem dependentes do meio ambiente, atendendo à relativa estabilidade das condições de temperatura da estufa.

Por outro lado, a repartição da experiência em dois periodos diferentes do ano (Verão e Inverno) não tem incidência sobre este fenô- 
meno. Portanto, parece-nos razoável pensar que a variação da expressão dos sintomas de degenerescência está ligada a fenômenos endógenos. Podemos aproximar-nos desta interpretação pelo simples fato de que, durante o desenvolvimento do aparelho vegetativo das plantas saudáveis, o comprimento dos entrenós exprime também um certo rítmo (Cours, 1951). No que diz respeito às plantas doentes, Bourriquet (1932), Storey \& Nichols (1938) fazem constatações análogas quando em condições habituais de cultura de mandioca.

Com o objetivo de obter indicações complementares sobre o significado deste problema, transplantamos sistematicamente cada um dos nós dos indivíduos apresentando irregularidades quanto à expressão da doença (clone " ( B"), anotando bem a sua colocação no caule e o estado da folha correspondente (Fig. 3).

Entre os indivíduos provenientes desta transplantação, alguns nunca mostraram, atra- vés dos meios de controle de que dispomos, a presença do agente patogênico. Mas, não há qualquer relação entre o estado da folha e o estado de saúde do botão axilar correspondente.

No entanto, continua a ser possivel o isolamento de porçōes indenes de agente patológico, mesmo a partir de uma planta apresentando sintomas de degenerescência. No mínimo, este fato implica que a repartição do agente infeccioso não é regular no interior da planta. A transplantação dos diferentes nós permite revelar esta heterogeneidade.

Se esta observação é interessante, no quadro de estudos das relações entre o agente patogênico e a planta-hóspede, também o é na aplicação prática, permitindo regenerar, pelo menos parcialmente, alguns clones, aproveitando as possibilidades oferecidas pela multiplica. ção vegetativa in vitro.

\section{FILA DE NÓS}

\begin{tabular}{|c|c|c|c|c|c|c|c|c|c|c|c|c|c|c|c|c|c|c|c|c|c|c|c|c|}
\hline \multirow[b]{2}{*}{ INDIVÍDUOS } & & 12 & \begin{tabular}{|l|l|}
3 & 4 \\
\end{tabular} & 5 & \begin{tabular}{|l|l|}
6 & 7 \\
\end{tabular} & 85 & 910 & 111 & 121 & 14 & 1511 & 11 & $8 \mid 15$ & 20 & 212 & $23|24| 25$ & 5 & 2 & 29 & 303 & 32.3 & 34,353 & $36 \sqrt[37]{37}$ & $38 / 3$ \\
\hline & 1 & $\cdot$ & & & & & & & 1 & & - & $a^{\circ}$ & $\bullet$ & & & & & & . & & & . & & . \\
\hline & II & & - & & & & & - & $\cdot$. & . & $\cdot$. &. & & & • & & - & & . & & & & & \\
\hline & III & & & & & & & & - & - & $\cdot$ & $\cdot$ & & & • & & & • & & • & & & .. & 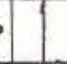 \\
\hline & IV & $\cdot$ & & & & & & - & . & & - & & •. & & & • & 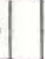 & & • & & & $\cdot$ & & $\cdot 1$ \\
\hline & V & $\cdot$ & & & & & & $\cdot$ & - & $1 \cdot$ & - & & • & . & & & - & - & & & & $\cdot$ & 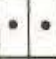 & \\
\hline & VI & & & & & & • & $\cdot$ & - & . & & & $\bullet$ & & • & & & 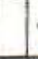 & $\bullet$ & • & & $\cdot$ & & $\cdot$ \\
\hline & VII & & - & & & & & & $\cdot$ & . & & & 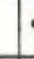 & & - & & - & - & & $\cdot$. & & & $\cdot$ & $\cdot$ \\
\hline & VIII & & . & & & & $\cdot \cdot$ & $\cdot$ & - & - & & & $\cdot$ & $\bullet$ & & & & & & & $\cdot$ & $\cdot$ & $\cdot$ & $\cdot$ \\
\hline & & 3 & & & & & & & 7 . & & & 3 & 5 & & & \begin{tabular}{l|l|l|l|l|l}
0 & 0
\end{tabular} & 3 & & & \begin{tabular}{l|l}
31 \\
\end{tabular} & & \begin{tabular}{|l|l|l|l|l}
0 & 6
\end{tabular} & & 45 \\
\hline
\end{tabular}

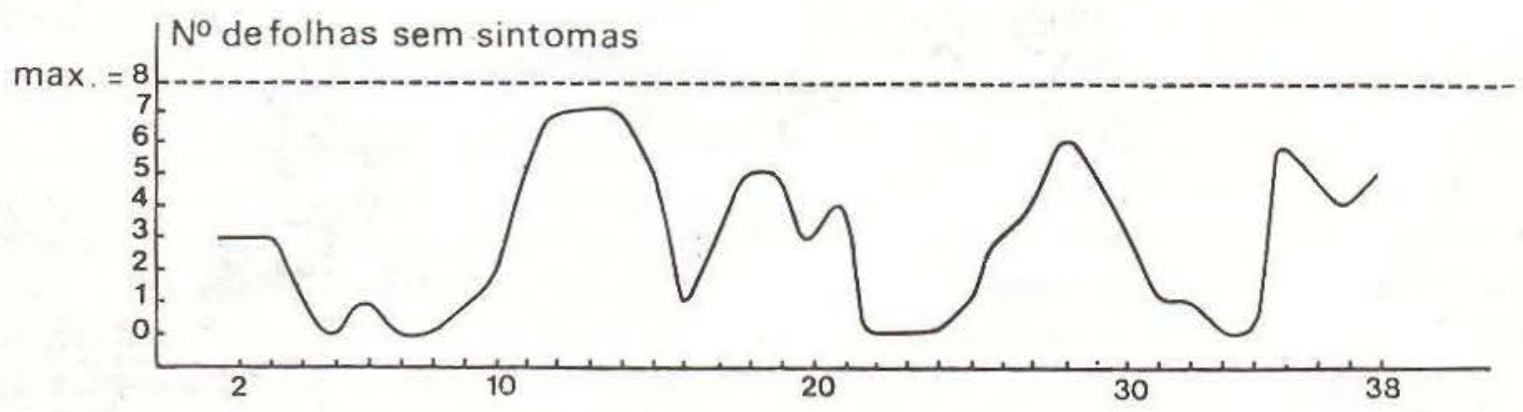

Fig. 3 - Presença de sintomas foliares do "Mosáico Africano da Mandioca" em funçāo da linha do nó. Efetivo: 8 individuos da linha " $\mathrm{C} B$ ". 


\section{B - TRANSMISSÃO DA DOENÇA PELO ENXERTO}

Em todos cs casos, a doença reve!ou-se transmissivel e os sintomas de degenerescência exprimiram-se ao nivel do garfo, nes casos em que o dispositivo experimental habitual fol utilizado (Fig. $1 \mathrm{H}$ ). Mas, a realização de enxertos inversos (garfo doente em cavalo saudável), mostrou que a transmissão do agente infeccicso pode operar-se nos dois sentidos.

\section{1) Conservação da intensidade dos sintomas}

Os sintomas do mosáico, que os clones de que dispomos exprimem, são mais ou menos fáceis de serem observados $\left(\begin{array}{lll}I_{1} & a & I_{4}\end{array}\right)$. É interessante constatar que há equivalência entre a intensidade dos sintomas manifestados pelo cavalo e a intensidade manifestada ao nível do garfo contaminado; por exemplo, $l_{1}$ relativamente aos enxertos saudáveis de "Baía de Along", sobre " $\mathrm{H}_{60}$, e $\mathrm{I}_{3}$ relativamente aos enxertos saudáveis de "Kaoli" ou "Abidjan" doentes. Ainda mais, esta intensidade mantem-se constante, mesmo após utilizar como estaca garfos aos quais a doença foi transmitida (Fig. $1 \mathrm{E}$ e F).

\section{2) Velocidade de propagação}

Quando existe transmissão da doença pelo enxertc, esta exprime-se unicamente ao nível das folhas do garfo que são recém-formadas; as folhas que existiam, já no começo da experiência, não são modificadas.

Constatamos, porém, que o tempo decorrido entre o enxerto e a expressão dos sintomas de degenerescência é variável em grandes proporçōes (15 dias a 2 meses).

Uma experiência mais sistemática, fazendo intervir apenas a dimensão do rebento, e mantendo iguais todos os outros fatores, mostra claramente (Fig. 4) que o tempo latente, entre o momento do enxerto e o da expressão da doença, é tanto mais longo quanto maior for o çarfo. Estes resultados indicam que a transmissão do agente patogênico intervém segundo um processo lento e progressivo.

Certas experiências de transplantações permitem completar esta interpretação. Quando um garfo manifesta sintomas de degenerescência, todas as estacas realizadas a partir dele exprimem a doença. Em contrapartida, antes da manifestação dos sintomas, apenas as

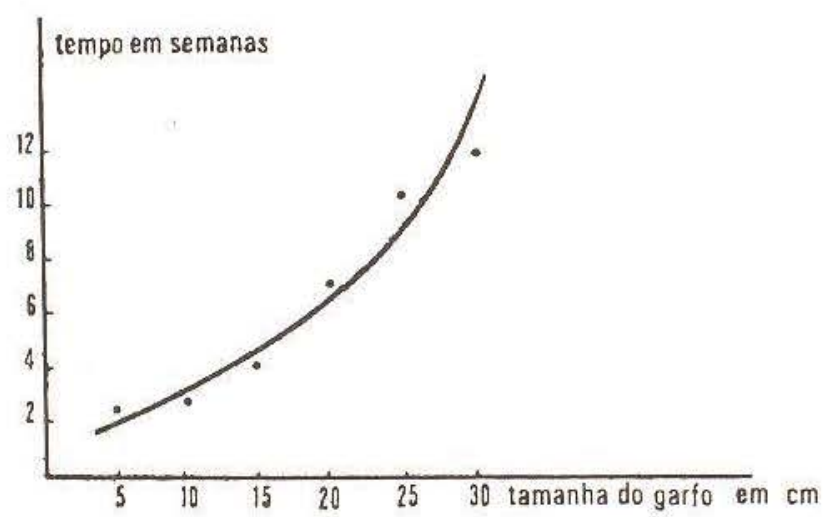

Fig. 4 - Tempo requerido para a expressão do "Mosaico Africano da Mandioca" em função do tamanho do garfo.

estacas provenientes da base dos garfos exprimem a degenerescênciá, enquanto que aquelas provenientes da parte superior continuam sãs.

Dispomos, deste modo, de um meio que nos permite analisar a velocidade de progressão do agente patogênico. Os resultados obtidos entre 15 dias e 3 meses, para garfos medindo respectivamente 5 a 30 centímetros, confirmam que a progressão é lenta: da ordem de alguns centímetros por semana.

\section{C - tentativas DE CUltura "IN vitro"}

Todos os clones de que dispomos, apresentando ou não sintomas de degenerescência, puderam ser multiplicados in vitro.

\section{1) Morfologia das plantas}

As plantas mantidas nas condições de cultura acima citadas são caracterizadas por um tamanho miniatura (Fig. 5A) e pela aquisição de uma morfologia foliar lembrando a morfologia das primeiras folhas de uma planta diretamente nascida de uma semente (Fig. 5B). Estes fenômeros são atualmente conhecidos em plantas cultivadas in vitro (Nozeran \& Bancilhon, 1972) .

No caso da mandioca, podemos assistir a uma redução do número dos lóbulos foliares. Nas plantas cultivadas, segundo as condições da estufa, este número varia entre 3 e 7 ; em contrapartida, naquelas que são cultivadas num tubo de ensaio, a folha nunca excede os 3 lóbulos. Esta redução pode conduzir a uma foIha simples, com uma série de intermediários que se diferenciam pelo número de lóbulos e 
pela redução mais ou menos importante das reentrâncias da folha (Fig. 5B). A aparição de uma morfologia foliar simplificada, de tipo juvenil, intervêm progressivamente em função do número de novas transplantações, mas, no caso da mandioca, há sempre persistência de um certo polimorfismo foliar

O comportamento, in vitro, dos clones atingidos pelos sintomas de degenerescência, não é modificado; mas, apesar de tudo, manifestam um desenvolvimento menor do que nos saudáveis. As condições de cultura diminuem a expressão da doença, não só no que diz respeito à percentagem de folhas modificadas ( $99 \%$ em condições de estufa e $6 \%$ in vitro para o clone "Kataoli" doente) mas também quanto ao grau de intensidade dos sintomas. Mas, estes últimos são tanto mais fáceis de ser observados quanto o clone se encontra mais atingido pela doença, ao início da exposição.

\section{2) Influência da temperatura}

Esta tem uma grande influência na expressão da doença. A temperatura habitualmente utilizada $\left(29^{\circ} \mathrm{C}\right)$, vimos que os sintomas são parcialmente mascarados. As temperaturas mais elevadas não se manifestam; isso já é uma indicação da existência de um efeito termoterapêutico. Em contrapartida, a $20^{\circ} \mathrm{C}$, a expressão dos sintomas é muito mais marcada. Esta constatação, relacionada com as experiências de termoterapia é interessante, na medida em que nos oferece a possibilidade de efetuar um primeiro controle rápido quanto ao efeito terapêutico das temperaturas elevadas.

Por outro lado, estas condições de temperatura relativamente baixas afrouxa muito $o$ desenvolvimento do aparelho vegetativo (Quadro 2): a produção é em média de 7 nós, em 5 meses, enquanto que o mesmo resultado é obtido em 6 semanas à temperatura de $29^{\circ} \mathrm{C}$.

QUADRO 2 - Comportamento de $\mathrm{H}_{60}$ são e doente em função das temperaturas $\left(20^{\circ}, 29^{\circ}\right.$ e $\left.37^{\circ} \mathrm{C}\right)$ após 3 meses de cuitura.

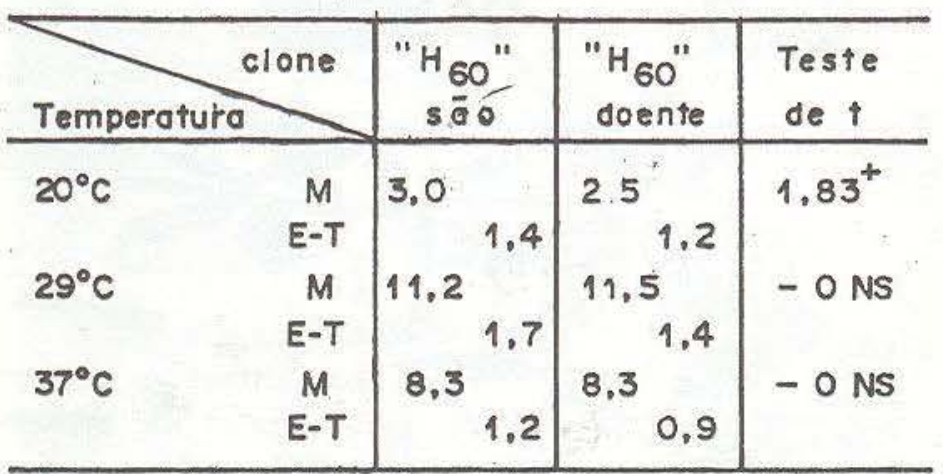

Média do número de nós por planta.

\begin{tabular}{|c|c|c|c|}
\hline Temperotura & $\begin{array}{c}\mathrm{H}_{60} \\
\text { s00 } \\
\end{array}$ & $\begin{array}{l}\text { " } \mathrm{H}_{60} " \\
\text { doente }\end{array}$ & $\begin{array}{l}\text { Teste } \\
\text { de } t\end{array}$ \\
\hline$\underset{E-T}{M}$ & $\begin{array}{ll}3,1 & \\
& 1,4\end{array}$ & ${ }^{2,2}$ & $3,28^{\circ \bullet}$ \\
\hline$\stackrel{M}{E-T}$ & $\begin{array}{r}12,5 \\
3,2\end{array}$ & $\begin{array}{r}12.4 \\
3.3\end{array}$ & $-O \mathrm{NS}$ \\
\hline$\underset{E-T}{M}$ & ${ }^{7,2} 3.2$ & $\begin{array}{r}7.4 \\
3,3\end{array}$ & - O NS \\
\hline
\end{tabular}

Tamanho médio $\mathrm{em} \mathrm{cm}$.

\begin{tabular}{|c|c|c|c|}
\hline & $\begin{array}{c}\text { "H } \mathrm{H}_{60} \text { " } \\
\text { são }\end{array}$ & $\begin{array}{l}\text { " } \mathrm{H}_{60} " \\
\text { doente }\end{array}$ & $\begin{array}{l}\text { Teste } \\
\text { de } t\end{array}$ \\
\hline$M$ & 3,0 & 1,2 & $9.66^{\circ \bullet}$ \\
\hline$E-T$ & 1.0 & 0,7 & \\
\hline M & 5,4 & 5,7 & $-1.06 \mathrm{NS}$ \\
\hline$E-T$ & 1,5 & 1.4 & \\
\hline$M$ & 3.7 & 3.6 & O NS \\
\hline E-T & 1,0 & 1.2 & \\
\hline
\end{tabular}

Média do numero de raizes por planta.

$$
M=\text { Mèdia observada }
$$

$E-T=$ Desvio-padröo

Teste $t=$ Teste de Student

Valor dos tábuas $5 \%=2,00$

$$
1 \%=2,66
$$

NS = Diferença nāo significativa entre os clones.

+ = Diferença ligeiro

- = Diferença muito signific ativa

NÚMERO EFETIVO $=45$ individuos para cada condicāo. 


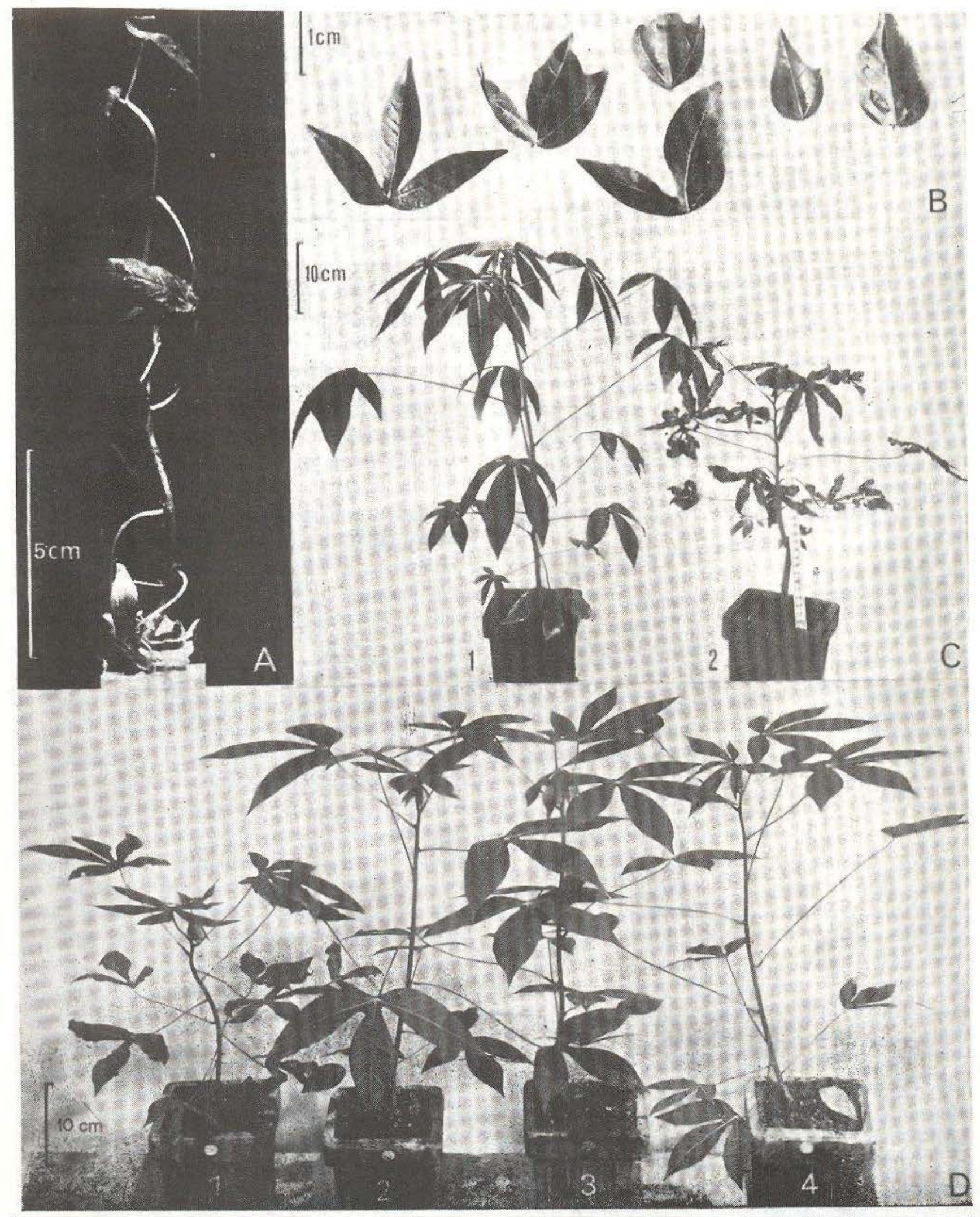

Fig. 5 - A) Pé de mandioca cultivado in vitro; $30^{\circ}$ transplantaçảo (clone " $\mathrm{H}_{\text {" }}$ saudável). a) raízes, b) folha sımples; B) Diferentes tipos foliares obtidos em cultura in vitro (clone " $\mathrm{H}_{\infty 0}$ " saudável); C) Individuos do clone "Kataoli", cultivados in vitro, exprimindo-se na estufa. 1) tratado pela termoterapia, 2) não tratado: D) Amostras do clone " $\mathrm{H}_{60}$ " cultivados in vitro, transferidos depois para a estufa (experiência "bloc"; 1) doente não tratado; 2) doente tratado: 3) saudável nāo tratado: 4) saudável tratado. 
Esta possibilidade de desenvolvimento reduzido apresenta um grande interesse no domínio da aplicação prática, pois nos permite construir, utilizando um pequeno volume e requerendo pouca manutenção, uma reserva de clones.

\section{3) Taxas de multiplicação}

Diversos fatores podem influenciar a eficácia das transplantações sucessivas realizadas in vitro. Numerosas tentativas mostraram que, com o meio de cultura utilizado, os melhores resultados eram obtidos quando se utilizavam, como estacas, indivíduos possuindo de 10 a 12 nós, a uma temperatura de $29^{\circ} \mathrm{C}$.

Nestas condições, e a partir da $3^{\text {a }}$ transplantação, estado durante o qual o comportamento das plantas in vitro está estabilizado, podemos avaliar a velocidade teórica da multiplicação vegetativa.

Os resultacios obtidos (Quadro 3) mostram, quando todas as outras condições são idênticas, as diferenças sensíveis em função dos clones. Apesar destas diferenças que podem ser atribuídas ou ao genótipo do clone ou aos efeitos da degenerescência, é possível obter, em todos os casos, uma taxa de multiplicação bem superior à observada na prática agrícola .

\section{D - TRATAMENTOS DE TERMOTERAPIA}

O material cultivado in vitro apresenta vantagens evidentes para a realização de tratamentos por termoterapia: material de tamanho pequeno (Fig. 5A); manutenção do aparelho vegetativo em condições ambientes idênticas e ao abrigo de qualquer contaminação; taxa higrométrica elevada no interior do tubo, permitindo a ação prolongada de temperaturas elevadas; controle rigoroso das condições do meio ambiente: meio de cultura, temperatura, umidade.

Tentativas preliminares mostraram que a temperatura de $40^{\circ} \mathrm{C}$ constitui o máximo compatível com o tempo de sobrevivência suficientemente longo das amostras: Elas podem manter-se em vida durante várias semanas, mas a morfologia das plantas é muito modificada, sobretudo pela redução notável do tamanho dos entrenós.

A $37^{\circ} \mathrm{C}$, porém, não constatamos modificações notórias no aparelho vegetativo; o tratamento pode, portanto, ser prolongado e, sobretudo, a transplantação continua possível.

\section{1) Busca de um tratamento eficaz}

Levando em conta todas estas indicações, estabelecemos experiências comparativas, nas duas temperaturas citadas. O resultado é que a cura das plantas é função, simultâneamente, da duração do tratamento e do grau mais elevado de temperatura (Quadro $n^{\circ}$ 4). Mas o emprego da temperatura mais eficaz (da ordem dos $40^{\circ} \mathrm{C}$ ) é limitado pelo estado de latência das plantas. Fomos, portanto, conduzidos a associar estas duas temperaturas em alternância (Fig. 6).

\section{2) Resultados obtidos}

No protocolo experimental mais correntemente utilizado, as plantas atingidas pelos sintomas de degenerescência são primeiramente

QUADRO 3 - Velocidade de multiplicação vegetativa in vitro dos diferentes clones

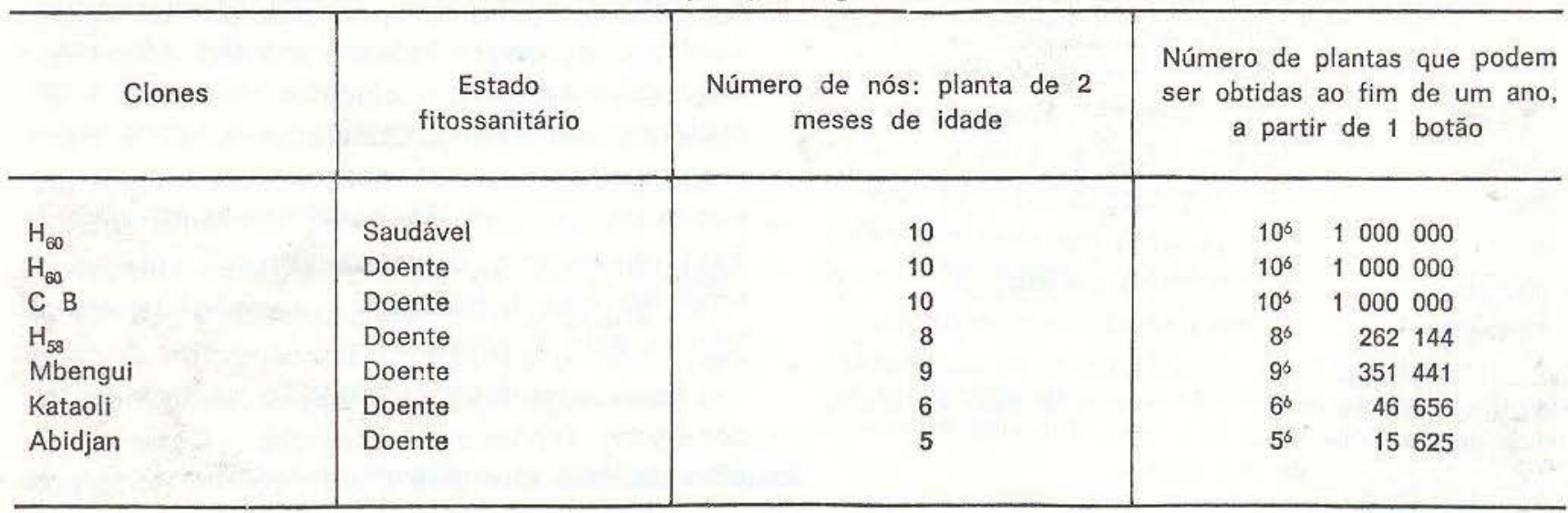


colocadas, 15 dias, numa estufa a $37^{\circ} \mathrm{C}$, antes de ser transferidas para uma temperatura de $40^{\circ} \mathrm{C}$, durante um mês e, para o final do tratamento, são reconduzidas, durante 45 dias a $\mathrm{T}^{\mathrm{O}}=37^{\circ} \mathrm{C}$ (Fig. 6) .

Este tratamento mostrou-se suficiente para a maioria dos clones, mas para outros, a ubtenção da cura definitiva necessita de um complemento ao tratamento, o qual consiste na realização de novas transplantações durante o período, cuja temperatura é de $37^{\circ} \mathrm{C}$. Deste modo, obtivemos a cura de todos os clones degenerescentes à nossa disposição.

\section{3) Controle da cura e retcrno às condições naturais}

A passagem das plantas cultivadas in vitro às condiçōes de estufa não apresenta dificuldades e triunfa em $98 \%$ dos casos. Os individuos transplantados adquirem, de novo, progressivamente, a morfologia normal (Fig. 5D). A passảgem às condições de cultura in vitro, com tratamento térmico, ou sem ele não tem ação aparente sobre os indivíduos provenientes de clones sãos. Em contrapartida, constatamos que os indivíduos que vêm dos clones degenerescentes, tratados in vitro pela termoterapia, deixam de exprimir os sintomas da doença e apresentam um desenvolvimento vegetativo comparável ao dos indivíduos inicialmente sãos.

Diversos controles, fazendo intervir enxertos associados a estacas, mostram a erradicação completa da doença.

Para o clone " $\mathrm{H}_{c c}$ ", fizemos uma experiência, a partir das 4 categorias (Fig. 5D) seguin-

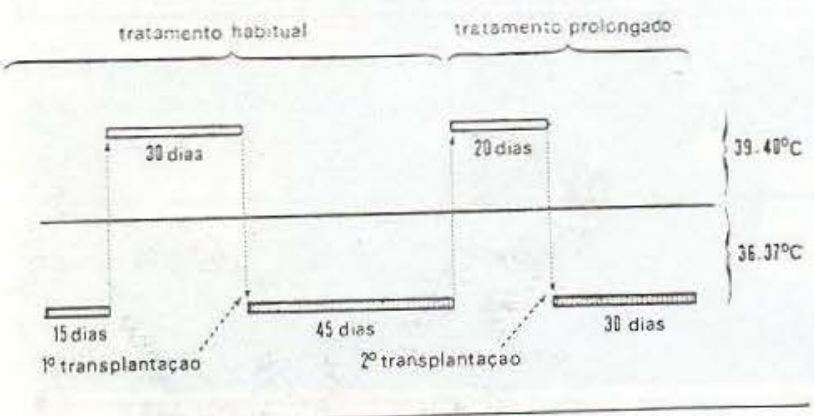

Fig. 6 - Esquema do tratamento pela termoterapia nas linhas da mandioca infectadas pelo "Mosaico Africano da Mandioca". tes, todas submetidas anteriormente às condiçōes de culturá in vitro: 1) saudável não tratada: 2) saudável tratada pela termoterapia; 3) doente não tratado; 4) doente tratado pela termoterapia.

Um estudo estatístico comparativo foi realizado a partir dos seguintes caracteres: tamanho dos indivíduos; número de nós; superfície foliar de $22^{a}$ a $25^{a}$ folha; rendimento, em peso, dos tubérculos.

Os resultacios obtidos confirmam que. as plantas que provém de clones degenerescentes tratados pela termoterapia in vitro não exprimem diferenças significativas relativamente ans testemunhos saudáveis correspondentes (Fereol, 1978) .

\section{DisCUSSÃo E CONCLUSÃo}

Este trabalho foi empreendido com um objetive muito preciso: o de encontrar condiçōes eficazes ao tratamento de plantas doentes por meio da termoterapia e obter uma multiplicação rápida do clone curado, com vista à sua utilização na prática agrícola. Estes prob!emas puderam ser resolvidos graças à utilização das culturas in vitro.

Anteriormente, o estudo do material de origem, cultivado em estufa, permitiu especificar o comportamento fitopátológico das plantas atingidas pelos sintomas de degenerescência.

Assim, a heterogeneidade da repartição do agente infeccioso manifestado em certos clones, permitiu a obtenção de indivíduos sem sintomas, provenientes da transplantação de certas partes doentes de uma planta. Este fato implica que a multiplicação do agente patogê. nico não é regular no interior da planta. A conservação de partes indenes em indivíduos que se encontram muito atingidos, estabelece um problema importante. Constatamos que a trans. plantação de nós com gomos podia levar à produção de um ramo são e de um ramo doente. Esta observação deixa supor a existência de uma barreira impedindo a invasə̃o de certos gomos pelo agente.

Bourriquet (1932), Storey \& Nichols (1938) observam fenômenos análogos. Com efeito, eles indicam que uma planta doente pode pos- 
QUADRO 4 - Taxa de cura de " $\mathrm{H}_{60}$ " doente em função da temperatura e da duração do tratamento. Säo consideradas como curadas as plantas que, após ser sujeitas aos diversos meios de controle à nossa disposiçăo, os ultrapassaram com sucesso

\begin{tabular}{|c|c|c|c|c|}
\hline & \multicolumn{2}{|c|}{$36-37^{\circ} \mathrm{C}$} & \multicolumn{2}{|c|}{$39-40^{\circ} \mathrm{C}$} \\
\hline & $\begin{array}{c}\mathrm{n} .^{\circ} \text { de plantas } \\
\text { submetidas ao teste }\end{array}$ & $n .^{\circ}$ de plantas sãs & $\begin{array}{c}\mathrm{n} \cdot{ }^{\circ} \text { de plantas } \\
\text { submetidas ao teste }\end{array}$ & $\mathrm{n} .^{\circ}$ de plantas sãs \\
\hline 3 semanas & 12 & 0 & 13 & 1 \\
\hline 4 semanas & 12 & 0 & 10 & 2 \\
\hline 5 semanas & 11 & 0 & 12 & 6 \\
\hline 6 semanas & 12 & 2 & 12 & 6 \\
\hline 12 semanas & 10 & 7 & & \\
\hline 16 semanas & 12 & 10 & & \\
\hline
\end{tabular}

suir certos ramos que não manifestam os sintomas de mosáico e que, ocasionalmente, uma estaca feita nesta planta pode conduzir a um indivíduo saudável. Casos similares foram assinalados em plantas de Tabaco infectadas pelo vírus do mosáico (TMV). Murakkshi \& Carlson (1975) mostraram que $50 \%$ das plantas regeneradas na cultura in vitro, a partir de placas foliares verde-escuros, revelaram-se indenes ao vírus.

As experiências de enxertos mostraramnos a existência de um certo tempo de latencia, precedendo a aparição dos primeiros sintomas na estaca. A partir de estacas de tamanhos diferentes e a partir de transplantações de nós isolados da estaca, não tendo ainda manifestado adoença, é possível determinar a velocidade de progressão do agente infeccioso. Levando em linha de conta os resultados obtidos (entre 15 dias e 3 meses para as estacas de 5 a $30 \mathrm{~cm}$ ) esta velocidade parece lenta. E razoável deduzir que o agente não deve ser veiculado passivamente pela seiva. Com base nestas observações, outras investigações essencialmente histológicas e histoquímicas, deveriam permitir a delimitação das vias de progressão do agente, bem como do processo utilizado na transmissão da doença.

As técnicas tradicionais de multiplicação vegetativa da mandioca deram resultados limitados. A utilização de hormônios para o meIhoramento das plantações permite, apesar de tudo, triplicar a produção (Chant \& Marden, 1958).

Segundo o nosso conhecimento, os melhores resultados foram obtidos pela C.I.A.T.('), por intermédio de microestacas, com toda a produção obtida, a partir de uma planta-mãe possuindo 300 nós que renderam 18.000 estacas comercializáveis num mesmo ano. As técnicas de multiplicação vegetativa in vitro permitiram-nos obter um rítmo de multiplicação particularmente elevado e, conseqüentemente, prever um ganho de tempo apreciável para a reconstituição dos clones. A adaptação da mandioca à cultura in vitro não levanta problemas. A eficiência da multiplicação é em função da origem do clone, mas continua a ser possível, mesmo nos casos mais desfavoráveis, obter resultados interessantes para a aplicação prática

A manutenção das plantas em cultura in vitro, pelo menos nas condições habitualmente utilizadas, traduz-se pela aquisição de uma morfologia particular, cujo caráter mais evidente é a miniaturização do conjunto formado pelo aparelho vegetativo. Uma observação interessante é que esta redução morfológica está ligada à aparição de caracteres que se manifestam habitualmente em plantas nascidas de uma semente, durante os primeiros estados de desenvolvimento, mostrando a aquisição de uma morfologia foliar simplificada de tipo juvenil. É possível que o estabelecimento destes carac-

(1) - C.I.A.T. Centro Internacional de Agricultura Tropical. 
teres esteja ligado, em parte, às modificações na organização anatômica, e também à redução do meristema terminal, como mostram investigações recentes (Nozeran \& Bancilhon-Rossignol, 1977; Gonod, 1977; Nozeran et al., 1979). A origem desta morfologia particular parece residir nas condições apresentadas pelo meio in vitro, e a temperatura parece ter um papel muito importante neste fenómeno.

Pelo menos, no quadro das experiências realizamos, estas condições provocam, nas plantas doentes, uma diminuição da intensiđade e da expressão dos siniomas do mosáico. $\mathrm{Na}$ grande maioria dos casos, e fazendo exceção às temperaturas elevadas $\left(37^{\circ}-40^{\circ} \mathrm{C}\right)$, cujo efeito já for analisado, trata-se de um simples disfarce da doença. O retorno às condiçōes de estufa permite, de novo, a expressão dos sintomas habituais. Pudemos constatar que certos individuos, quando a $29^{\circ} \mathrm{C}$, curavam-se espontaneamente. As razões deste fenômeno ficam por expiicar. O estado atual das investigaçōes não permite escolher entre o efeito direto do meio ambiente e a aquisição feita pela planta, sob estas condições, de propriedades fisiológicas eventualmente ligadas a um estado juvenil mais ou menos acentuado - estas propriedades podendo limitar a expressão dos sintomas ou mesmo a multiplicação do agente patogênico. Esta interpretação poderia iigar-se ao fato de o meristema terminal, assim como o embrião das plantas contaminadas, não alojarem o agente da doença (Kartha \& Gamgorg, 1974).

Os tratamentos de termoterapia aplicacius às plantas cultivadas in vitro, revelaram-se eficazes relativamente ao material que utilizamos. Estes nos permitiram dispor de novos materiais indenes de sintomas de mosaico, pelo menos quanto aos marcadores que usamos e com base nos controles que estabelecemos. É evidente que esta parte do trabalho deveria ser completada pela adaptação ao material das técnicas modernas de virologia, necessitando, num primeiro passo, da determinação e do isolamento do agente patogênico.

É preciso sublinhar que a realização do tratamento em plantas cultivadas in vitro, favorece dadas a miniaturização e as condições particulares do meio ambiente, o sucesso das tentativas de termoterapia. A duração dos tratamentos é tal que podemos dificilmente imaginar a sua aplicação às plantas cultivadas em condições habituais.

Falta ainda definir os modos de ação da termoterapia. Vimos que, para certos clones, a cura é obtida pela ação isolada do tratamento térmico, enquanto, para outras, é necessário fazer transplantaçōes durante o tratamento. Algumas experiências de termoterapia feitas in vivo por Chant (1959), dão resultados que estẽo de acordo com os precedentes. Eles demonstraram que o transplante de ramos recentemente formados sobre plantas doentes durante o tratamento, permite chegar mais facilmente à cura, do que no caso do transplante de plantas inteiras no fim do tratamento.

Estes fatos autorizam a pensar que as transplantações durante o tratamento intervém isolando certas porções da planta, indenes do agente infeccioso. É preciso notar que, a partir da segunda transplantação, subsiste apenas o material formado durante o tratamento. E pro. vável que, pelo menos nos casos dos clones que estudamos, as temperaturas elevadas tenham por efeito impedir a multiplicação do agente - sem necessariamente o destruir e que apenas as partes da planta recentemente formadas thes seriam indenes. Experiências de transplantação, nó a nó, de indivíduos que receberam um tratamento parcial de termoterapia, parecem verificar esta hipótese. Os resultados obtidos mostraram que as estacas da base (existindo já antes do tratamento), dăo origem a indivíduos que manifestam os sintomas da degenerescência, enquanto que as estacas da parte superior (formadas durante o tratamento) originam plantas saudáveis.

O método que propomos parece oferecer perspectivas interessantes, sobretucio quando confrontado a outros utilizados com sucesso, na tentativa de eliminar as doenças virais na mandioca: criação de híbridos resistentes (Magoon et al., 1970), culturas de meristemas (Kartha \& Gamgorg, 1974; Berbee et al., 1974).

Por um lado, a miniaturização das plantas cultivadas in vitro permite o tratamento simultâneo de um grande número de indivíduos em circuito fechado, condicionado, de tamanho reduzido, reforçando a eficiência dos tratamen- 
tos. Por outro lado, esta técnica permite proceder imediatamente a uma multiplicação vegetativa acelerada conduzindo a reconstituição rápida de um clone saudável, desde que não sofra contaminações.

\section{Agradectmentos}

Este trabalho foi proposto pelo Professor Nozeran, a quem agradecemos por seus inúmeros conselhos, assim como pelo material que trouxe de uma missão ao Vietnã. O material africano foi-nos concedido graças à gentileza do sr. Tardieu (I.R.A.T.).

\section{SUMMARY}

Cassava clones traditionally cultivated in Africa, frequentty show some degenerating signs ("African Cassava mosaic"). Refering to an healthy clone from VietNam, the distribution, transmission and progression of the causal agent have been observed from cutting and graft experiments. In vitro culture enable us to adjust thermotherapy treatments leading to the cure of all the studied clones and to obtain an accelarated vegetative multiplication leading to the rapid reconstitution of healthy clones.

\section{REFERENCIAS BIBLIOGRAFICAS}

BECK, B.D. \& CHANT, S.R.

1958 - A preliminary investigation of the effect of mosaic virus on Manihot utilissima Pohl in Nigeria. - Tropical Agriculturist 1958, p. 59-64, janeiro.

BERBEE, F.H.; BERBEE, J.G.; HILDEBRANDT, A.C.

1974 - Induction of callus and virus - symptomless plants from stem tip cultures of cassava in vitro. Annual Meeting Abstracts, 8: 421.

BORRIQUET, G.

1932 - Les Maladies du Manioc à Madagascar. Rev. Path. Veg., 19: 290.

BOUZID, S.

1973 - Utilisation des cultures in vitro pour la solution de problèmes posés pour l'amélioration des agrumes (en particulier multiplication végétative). Thèse 3ème cycle. Fac. Sc. Tunis, 78 .

BOUZID, S. \& LASRAM, M.

1971 - Utilisation des cultures in vitro pour l'obtention de clônes de Citrus homogènes et de bon état sanitaire. 8 e Cong. Inst. Agron. Mediter. "Holland Peal" C.L.A.M. II, 1-16.
CHANT, S.R.

1959 - A note of the inactivation of mosaic virus in Cassava (Manihot utilissima) by heat treament. Exp. Journal Agric., 27: 55-58.

CHANT, S.R. \& MARDEN, J.A.

1958 - A method for the rapid propagation of Cassava Cuttings. Tropical Agriculture, Trinidad, 35 (3): 195-199, tabl. (5), Ill. bibl., 6 ref.

COURS, G.

1951 - Le Manioc à Madagascar. Mémoire de l'Institut Scientifique de Madagascar - Série B. Tome III. Fascículo 2.

FAVRE, J.M.

1970 - Influence de facteurs internes sur la cinétique d'enracinement de la vigne cultivée in vitro. Rev. Gen. Bot., 77: 519-562.

1973 - Effects corrélatifs de facteurs Internes et externes sur la rhyzogenese d'un clône de vigne cultivée in vitro. Rev. Gen. Bot., 80 , 273-361.

FEREOL, L.

1978 - Multiplication végétative et élimination des phénomènes de dégénérescence chez des clônes de Manioc (Manihot esculenta CRANTZ) cultivés in vitro. Thèse 3ème cycle, Université Paris-Sud (Orsay).

GALZY, R.

1964 - Technique de thermothérapie des viroses de la vigne. Ann. epiphytes, 15/3: 245-256.

GONOD, M.C.

1977 - Morphogénése de divers clônes de Dalhia variabilis multipliés végétativement in vitro: Miniaturisation, rejeunissement, variabilité. Thèse 3ème cycle, Université Paris-Sud (ORSAY).

GRENAN, S.

1976 - Analyse de phénomènes morphogénétiques posés par la multiplication végétative invitro de la pomme de terre: Solarum tuberosum L. var. B.F. 15 - Thèse Université Paris-Sud.

JENNINGS, D.L.

1957 - Further studies of breeding Cassava for vlrus resistance. East African Agricultural Journal, 22 (4): 213-219.

1960 - Observations on virus diseases of Cassava in resistant and susceptiple varieties 1, Mosaic disease II. Brown streak disease. Empire journal of experimental Agriculture, (28): $23-34$ et $261-270$.

KARTHA, K.K. \& GAMBORG, O.L.

1974 - Elimination of Cassava mosaic disease by meristem culture. Phytopathology, 65: 826828.

KITAJIMA, E.W. \& COSTA, A.S.

1966 - Spheroidal particles associated with Cassava mosaic virus. Bragantia, 25: 211-221. 
MAGOON, M.L.; KRISHNAN, R.; JAYABAY, K.

1970 - Cytogenetics of the $F_{1}$ hybrid between Cassava and ceara rubber and its back cross. Genética, 41: 425-436.

MARAKISHI, H.H. \& CARLOS, P.S.

1957 - Regeneration of virus free plants from dark green Islands of Tobacco mosaic virus infected tobacco leaves. Phytopathology, 66: 931-932.

NOZERAN, R. \& BANCILHON-ROSSIGNOL, L.

1972 - Les cultures in vitro en tant que technique pour l'approche de problèmes posés par l'amélioration des plants. Ann. Amélior. Plantes, 22: 167-185.

1977 - La multiplication végétative chez les végétaux vasculaires - Soc. Bot. F.; Coll. Mult. végét. 124: 59-96.

NOZERAN, R.; BANCILHON-ROSSIGNOL, L.; GRENAN, G.

1977 - Nouvells possibilités d'obtention et de multiplication rapide de clônes sains de pomme de terre (Solarum tuberosum) L.C.R. Acad. Sci. Paris, - t: 285

NOZERAN, R.; DUCREUX, G.; NEVILLE, P.; BANCILHONROSSIGNOL, L.

1979 - Ramifications et corrélations morphogènes - Soc. Bot. Fr.; Act Bot (sous presse).
PANNETIER, C. \& LANAUD, C.

1976 - Divers aspects de l'utilisation possible des cuitures in vitro pour la multiplication de l'Ananas Comosus LL. MERR, variété "Cayenne lisse". Fruits, 31 (12): 739-750.

SIHASCHAKR, A.

1974 - Contribution à l'étude du phénomène de tubérisation et premiers essais de multiplication végétative en culture "in vitro" de la patate douce. Mémoire diplôme d'études approfondies. Orsay.

STOREY, H.H. \& NICHOLS, R.F.W.

1958 - Virus diseases of East African plants. VII. A field experiment in the transmission of Cassava mosaic. East Afric. 5, III, 6: 446449

SILVA, D.H.

1962 - Obtaining an antiserum against Cassava mosaic virus. - Bragantia, $21 \mathrm{XClX}-\mathrm{C}$ II.

VALAT, C. \& MUR, G.

1976 - Thermothérapie du Cardinal rouge. Progres. agric. vitic, 6: 200-202.

(Aceito para publicação em 03/09/79) 